\title{
THE RELATIONSHIP BETWEEN THE ANTHROPOMETRIC MEASURES AND RESPIRATORY FUNCTIONS OF TOBACCO WORKERS
}

\author{
PETER OLAITAN AIYEDUN ${ }^{1}$, SALAMI OLASUNKANMI ISMAILA ${ }^{* 1}$, DAVID \\ OJO $^{2}$, GIDEON OLABODE ADENIRAN ${ }^{1}$ \\ ${ }^{1}$ Department of Mechanical Engineering, College of Engineering, Federal University of \\ Agriculture, Abeokuta, Ogun State, Nigeria \\ ${ }^{2}$ Department of Microbiology, College of Biological Sciences, Federal University of \\ Agriculture, Abeokuta, Ogun State, Nigeria
}

\begin{abstract}
The aim of this research was to establish the relationship between some anthropometric measurements and peak expiratory flow rate of tobacco factory workers. Eighty permanent workers who had been employed for at least three years with no history of cardiovascular disease were involved with the study. The measured anthropometric data (chest width and depth, height and weight) were analyzed using SPSS (V 16.0) to develop predictive models for PEFR of tobacco factory workers. It was concluded that the developed models could determine the PEFR of workers in a tobacco manufacturing company.
\end{abstract}

Keywords: dust, peak expiratory flow rate, lung function

\section{INTRODUCTION}

The concept of ergonomics is central to the discussion on the effect of health and safety on productivity [1]. The aim of ergonomics is to ensure the well-being of the worker by attaining optimal working conditions while using the most suitable physical characteristics and psychological capability [2]. Occupational and environmental respiratory diseases have a long history with respiratory disorders among tobacco workers [3]. As early as the beginning of the 18th century, 'Ramazzini' wrote about diseases of tobacco workers [4].

The study of the relationship between health and the environment led to the conclusion that ill-health was because there was an imbalance between human beings and the environment. Technology changes work contents and create new hazards while the social reformers educate the public on the new dangers associated with technology. The rate of health issues associated with exposure to environmental and work-related toxic substances has increased in the last few years [5]. Inhaling work-related toxic substances that contain an excessive amount of dust, fumes, smoke, gases, vapors, or mist may lead to lung disease while a worker that smokes is more prone to a lung disease. Heat, poor ventilation and closed-in working areas increase the risk of diseases. Akanbi et al. [6] found significant differences between the pre-work and post-work PEFR for both the exposed and unexposed workers with the pre-work values lower than the post-work values for workers in the cement industry.

\footnotetext{
* Corresponding author, email: ismailaso@ funaab.edu.ng

(c) 2018 Alma Mater Publishing House
} 
Peak expiratory flow rate (PEFR) according to Robert and Crapo [7] is one of the pulmonary lung- function tests that provide a quantifiable measure of lung function. It is used to test and monitor diseases that affect the lung function, monitor the effects of the environment, monitor occupational exposures, assess risks of surgery and in pre-employment evaluation or for insurance. The PEFR measures the movement of air into and out of the lung during breathings. When a lung function test is used in monitoring the effects of occupational exposures or as an aid in diagnosis, the signal is the subject's result compared with the expected result for the subject without disease but similar in the personal characteristics that determine lung function such as gender, age, height, and weight [7]. Monitoring of PEFR is useful only when adequate baseline studies are available for comparison. A change in a subject's baseline value is more likely to indicate pulmonary injury than the traditional comparison of values measured in the subject with reference values obtained from population studies as a change from a baseline of 5 to 10 percent may be significant for a person [7].

In developing countries, millions of the people on a daily basis worked in a dusty environment, among which is a tobacco company. The health hazards of tobacco leaves may differ from one to the other depending on where they are grown, the part where they are obtained from the tobacco plant, and the attention provided during growing and harvesting. Some harmful agents that contaminate the leaves are silica, insecticides, nicotine, and any other organic dust [8].

The reported symptoms of tobacco workers are a cough, phlegm production, and chest tightness, impairment of lung functions, bronchial asthma, a headache, fatigue and carcinoma of lungs, stomach, and colon. In an exposure-response study, there is a need to validate the association between exposure and health effects. This relationship may depend on variableness of length of exposure and classification of workers while exposure variation depends on agent-related factors, work content, the task performed, as well as production and environmental characteristics [9]. To estimate the relationship between ill-health and health effects, exposure variability and proper classification of workers become very important in occupational exposure studies [10]. Logistical constraints on time and cost prevent occupational sampling strategies for measuring the entire workforce [11]. A group-based system is, therefore, more preferable in most cases as they are less demanding in terms of logistics than individual-based strategies [12]. A group-based system involves representative measurements on some people in an occupational group that are similarly exposed, estimating the average exposure values and assigning the average values to all group members [13]. Symanski et al. [14] noted that the variability in exposure groups can be evaluated, which will be helpful to assess different grouping schemes.

Daily variability in exposure and between workers in an occupational group can assess whether occupational exposure limits [5] have been exceeded to classify workers into similar exposed groups [15]. Viegi et al. [16] reported that respiratory or nasal symptoms in the cigar and cigarette making workers were higher than the control. Also, Mustjbegovic et al. [3] showed that tobacco workers had lower forced vital capacity (FVC), forced expiratory volume in $1 \mathrm{sec}$. Mwaiselage et al. [17] found that exposure to respiratory dust had a significant correlation with a decrease in percentage cross-shift of peak expiratory flow (PEF) values. Abdel Rasoul et al. [18] found changes in the mean values of different spirometric measurements among exposed workers compared with the control group, which they attributed to tobacco dust. The preliminary study carried out showed that many cigarettes manufacturing workers complained of respiratory symptoms and continuous exposure to tobacco dust reduced workers' lung volume and peak expiratory flow rate (PEFR).

Workers in developing countries are often from lower socio-economic classes and are hired without appropriate training and deployed at the work site without proper personal protective equipment (PPE) or ventilation. The level of awareness about occupational hazards among factory workers is limited. Thus, how working in dusty environments affects health and safety is a serious concern [19]. The main occupational hazard during tobacco processing is dust. The care used in growing, harvesting and the additives in form of flavour during blending makes tobacco dust to pose more risk to the respiratory tract than mere organic dust as many of these chemicals cause cancer and various other ailments [20].

The World Health Organization [21] estimated that in 2004 alone, tobacco caused 5.4 million deaths.

Kjaergaard et al. [22] stated that tobacco dust can cause a defective vision, dull-aching headache and eye irritation among tobacco workers. Tobacco workers inhale, swallow and expose their skin and mucous surface to significant amounts of particulate tobacco. The constituents of tobacco get absorbed into the body, get bioactivated and result in an increased risk of developing ailments for which tobacco consumption is a major risk 
factor, including chronic obstructive pulmonary disease, cardiovascular system abnormality, carcinomas and premature death.

The aim of this study was to assess the effect of exposure to tobacco dust on lung function and its relationship with anthropometric data on tobacco factory workers in Ibadan, Oyo State.

\section{METHODS}

\subsection{Study Population}

Eighty out of 302 male permanent workers that had been employed for at least three years with no history of cardiovascular disease were involved in the study. Participants were informed a few days before the study commenced, and they were given adequate information. The consents of the participants were obtained before the start of the study.

A modified British medical research council respiratory disease questionnaire $[23,24]$ was administered to all subjects who were grouped into two classes of directly exposed and indirectly exposed.

The directly exposed workers were those in all production departments: Primary Manufacturing Department (PMD), Secondary Manufacturing Department (SMD), Filter Rod and Maintenance Department.

The indirectly exposed workers were those in the Human Resources Department, Information Technology Department, Engineering and Logistic and Supply Chain Department.

The selection criteria were ages between 20 and 40 years, length of work in the tobacco factory of not less than three years ( 3 years), no smoking and no history of a pulmonary or cardiac disease.

\subsection{Measurement of Peak Expiratory Flow Rate (PEFR)}

The pulmonary function test was done as each subject took in a deep breath, put the mouthpiece of the miniWright peak flow meter into the mouth and close the lips around the mouthpiece. In one breath, the subject blew out hard and quickly until he emptied out all the air from the lungs. The PEFR values were measured with a mini-Wright peak flow meter (Hudson RCI 1993, 48031E, England). Three trials were made per subject and the highest reading was taken as the worker's PEFR.

In each subgroup of classifications, PEFR values were measured in the morning before the work shift (between 6 a. m. and 7 a. m.) and again after the morning work shift ( 2 p. m.).

Heights (without wearing shoes) of the subjects were measured using a stadiometer (Detecto, Cardinal Scale Manufacturing Company, USA) with the subject standing erect, head oriented in the Frankfurt plane and feet together. Weights of the subjects were measured while they wore light clothing using the stadiometer. The chest depth and chest width were measured with a Vernier calliper (Mitutoyo, Japan) to determine the chest area. The chest area was calculated using Equation 1 [25]:

$$
\left(\frac{\pi \times \mathrm{A} \times \mathrm{B}}{4}\right)
$$

Where: $\mathrm{A} \mathrm{i}=$ chest width and $\mathrm{B}$ - chest depth.

\subsection{Measurement of Peak Expiratory Flow Rate (PEFR)}

The calculated chest area, PEFR values and other parameters (age, height, weight and years of exposure) were analyzed using linear regression analysis and descriptive statistics on the Scientific Package for Social Science (SPSS) version 16.0. to obtain the PEFR prediction equations.

Multiple linear correlations were obtained from the relationship with PEFR as the dependent variable, and age, height, weight, chest area and years of exposure to tobacco in the factory (experience) as independent variables. 


\section{RESULTS AND DISCUSSION}

The means of age, height, weight, chest area, years of exposure, PEFR before work and PEFR after the work of the directly exposed workers were $32.18( \pm 5.42)$ years, $168( \pm 6.69) \mathrm{cm}, 66.63( \pm 7.63) \mathrm{kg}, 0.12( \pm 0.02) \mathrm{m}^{2}, 4.93$ $( \pm 1.25)$ years, $492( \pm 16.36) \mathrm{L} / \mathrm{min}$ and $458( \pm 41.83) \mathrm{L} / \mathrm{min}$ respectively (Table 1$)$.

Table 2 presents the descriptive statistics of the indirectly exposed tobacco workers. The means of age, height, weight, chest area, years of exposure, PEFR before work and PEFR after the work of the indirectly exposed workers were $33.33( \pm 4.40)$ years, $172.23( \pm 5.89) \mathrm{cm}, 70.05( \pm 6.03) \mathrm{kg}, 0.12( \pm 0.02) \mathrm{m}^{2}, 4.25( \pm 1.30)$ years, $512.75( \pm 21.48) \mathrm{L} / \mathrm{min}$ and $494.60( \pm 27.89) \mathrm{L} / \mathrm{min}$ respectively.

Table 1. Descriptive statistics for the directly exposed workers $(\mathrm{N}=40)$.

\begin{tabular}{|l|c|c|c|}
\hline Parameter & Range & $\boldsymbol{M}$ & $\boldsymbol{S} \boldsymbol{D}$ \\
\hline Age (years) & $24.00-40.00$ & 32.18 & 5.42 \\
\hline Height $(\mathrm{cm})$ & $147.50-180.00$ & 168.00 & 6.69 \\
\hline Weight(kg) & $57.00-90.00$ & 66.63 & 7.63 \\
\hline Years of exposure (years) & $3.00-7.00$ & 4.93 & 1.25 \\
\hline Chest Area (m $\left.{ }^{2}\right)$ & $0.08-0.15$ & 0.12 & 0.02 \\
\hline PEFR before Work (L/min) & $440.00-520.00$ & 492.00 & 16.36 \\
\hline PEFR after work (L/min) & $310.00-500.00$ & 458.00 & 41.83 \\
\hline
\end{tabular}

Note: PEFR- peak expiratory flow rate; $M$ - mean; $S D$ - standard deviation

Table 2. Descriptive statistics for the indirectly exposed workers $(\mathrm{N}=40)$.

\begin{tabular}{|c|c|c|c|}
\hline Parameter & Range & $\boldsymbol{M}$ & $\boldsymbol{S D}$ \\
\hline Age (years) & $25.00-40.00$ & 33.33 & 4.40 \\
\hline Height $(\mathrm{cm})$ & $161.50-187.00$ & 172.23 & 5.89 \\
\hline Weight $(\mathrm{kg})$ & $59.00-87.00$ & 70.05 & 6.03 \\
\hline Years of exposure (years) & $3.00-7.00$ & 4.25 & 1.30 \\
\hline Chest Area (m $\left.{ }^{2}\right)$ & $0.08-0.18$ & 0.12 & 0.02 \\
\hline PEFR before Work (L/min) & $480.00-560.00$ & 512.75 & 21.48 \\
\hline PEFR after work (L/min) & $430.00-550.00$ & 494.60 & 27.89 \\
\hline
\end{tabular}

Note: PEFR-= peak expiratory flow rate; $M$ - mean; $S D$ - standard deviation

Table 3 presents the mean values of the anthropometric dimensions and PEFR of the workers according to their departments. It shows that workers in PMD are some susceptible to the negative effects of tobacco dust inhalation with the highest percentage decrease in PEFR of $20.18 \%$. This is followed by SMD (7.47\%), information technology $(4.46 \%)$, logistics and supply chain $(4.01 \%)$, human resources $(3.29 \%)$, engineering $(3.27 \%)$, filter rod $(2.96 \%)$ and maintenance $(2.95 \%)$ departments.

Table 3. Mean values of anthropometric measures and pre- and post-PEFR of the workers based on departments.

\begin{tabular}{|c|c|c|c|c|c|c|c|}
\hline Department & Age & Height & Weight & $\begin{array}{c}\text { Chest } \\
\text { area } \\
\left(\mathrm{m}^{2}\right)\end{array}$ & $\begin{array}{c}\text { Pre- shift } \\
\text { PEFR } \\
(\mathrm{L} / \mathrm{min})\end{array}$ & $\begin{array}{c}\text { Post-work } \\
\text { PEFR } \\
(\mathrm{L} / \mathrm{min})\end{array}$ & $\begin{array}{c}\% \text { shift } \\
\text { change }\end{array}$ \\
\hline SMD & 30.20 & 168.89 & 65.80 & 0.11 & 501.00 & 467 & -7.47 \\
\hline PMD & 32.30 & 168.10 & 64.60 & 0.13 & 480.00 & 406.00 & -20.18 \\
\hline Filter Rod & 32.10 & 168.99 & 65.50 & 0.14 & 495.00 & 481.00 & -2.96 \\
\hline Maintenance & 34.10 & 165.16 & 70.60 & 0.11 & 492.00 & 478.00 & -2.95 \\
\hline Human Resources & 32.90 & 170.66 & 70.50 & 0.11 & 514.00 & 498.00 & -3.29 \\
\hline $\begin{array}{c}\text { Information } \\
\text { Technology }\end{array}$ & 34.20 & 173.66 & 68.70 & 0.13 & 510.00 & 489.00 & -4.46 \\
\hline Engineering & 32.30 & 173.42 & 70.70 & 0.13 & 518.00 & 501.00 & -3.27 \\
\hline $\begin{array}{c}\text { Logistics and Supply } \\
\text { Chain }\end{array}$ & 32.70 & 168.58 & 70.30 & 0.12 & 509.00 & 490.40 & -4.01 \\
\hline
\end{tabular}

Note: SMD - secondary manufacturing department; PMD - primary manufacturing department; PEFR - peak expiratory flow rate

Table 4 presents the model summary of PEFR for the directly exposed group with $\mathrm{R}^{2}=0.406$ while Table 5 presents the model summary of PEFR for the indirectly exposed group with $R^{2}=0.884$. 
The value of $\mathrm{R}^{2}=0.884$ obtained showed that the predictors (age, height, weight, chest area and year of exposure) explained $88.4 \%$ of the variation in PEFR.

Equation 2 is the model to estimate PEFR for the directly exposed group.

PEFR $_{\text {directly exposed }}=246.85-1.68($ age $)+1.88($ height $)+0.28($ weight $)+2.35$ (year of exposure $)-239.40($ chest area)

Equation 3 is the model to estimate PEFR of the indirectly exposed group.

PEFR $_{\text {indirectly exposed }}=221.89-4.51($ age $)+2.49($ height $)+0.15($ weight $)+.39($ year of exposure $)-71.32($ chest area)

Table 4. Model summary for the directly exposed group.

\begin{tabular}{|c|c|c|c|c|}
\hline \multirow[b]{2}{*}{ Model } & \multicolumn{2}{|c|}{ Unstandardized Coefficient } & \multirow{2}{*}{$\frac{\text { Standardized Coefficient }}{\beta}$} & \multirow[t]{2}{*}{$t$} \\
\hline & $B$ & $S E$ & & \\
\hline (Constant) & 246.85 & 66.14 & & $3.73 *$ \\
\hline Age (years) & -1.68 & 0.54 & -0.56 & $-3.12 *$ \\
\hline Height $(\mathrm{cm})$ & 1.88 & 0.42 & 0.73 & $4.26 * *$ \\
\hline Weight (kg) & 0.28 & 0.31 & 0.13 & 0.89 \\
\hline Exposure (years) & 2.35 & 2.01 & 0.18 & 1.17 \\
\hline Chest area $\left(\mathrm{m}^{2}\right)$ & -239.40 & 122.29 & -0.26 & -1.96 \\
\hline
\end{tabular}

Notes. $B$ - unstandardized coefficient; $S E$ - standard error; $\beta$ - standard coefficient; $t$ - Student's $t$; significant at $p<.05 ; * *$ significant at $p<.001$

When the data for the directly exposed were divided by the year of exposure [26], the model for predicting the PEFR improved with $\mathrm{R}^{2}=0.986$. The improved model is stated in Equation 4:

$$
\text { PEFR } \left.\left._{\text {improved directly exposed }}=5.26-2.46(\text { age })+3.28 \text { (height }\right)+0.41 \text { (weight }\right)-256.09 \text { (chest area) }
$$

Table 5. Model summary for the indirectly exposed group.

\begin{tabular}{|c|c|c|c|c|c|}
\hline \multirow[t]{2}{*}{ Model } & \multicolumn{3}{|c|}{ Unstandardized Coefficient } & \multirow{2}{*}{$\frac{\text { Standardized Coefficient }}{\beta}$} & \multirow[t]{2}{*}{$t$} \\
\hline & $B$ & & $S E$ & & \\
\hline & (Constant) & 221.89 & 40.88 & & $5.43 * *$ \\
\hline & Age (years) & -4.51 & 0.43 & -0.92 & $-10.42 * *$ \\
\hline & Height $(\mathrm{cm})$ & 2.49 & 0.25 & 0.68 & $10.10 * *$ \\
\hline & Weight $(\mathrm{kg})$ & 0.15 & 0.25 & 0.04 & 0.60 \\
\hline & Years of exposure & 2.39 & 1.41 & 0.14 & 1.67 \\
\hline & Chest area $\left(\mathrm{m}^{2}\right)$ & -71.32 & 69.72 & -0.07 & -1.02 \\
\hline
\end{tabular}

Note: $B$ - unstandardized coefficient; $S E$ - standard error; $\beta$ - standard coefficient; $t$ - Student's $t$; **significant at $p<.001$

Table 6: Improved model summary for the directly exposed group.

\begin{tabular}{|c|c|c|c|c|c|}
\hline \multirow[t]{2}{*}{ Model } & \multicolumn{2}{|c|}{ Unstandardized Coefficient } & \multirow{2}{*}{\multicolumn{2}{|c|}{$\frac{\text { Standardized Coefficient }}{\beta}$}} & \multirow[t]{2}{*}{$t$} \\
\hline & $B$ & $S E$ & & & \\
\hline & (Constant) & 5.26 & 2.52 & & $2.09 *$ \\
\hline & Age (years) & -2.46 & 0.61 & -0.15 & $-4.05^{* * *}$ \\
\hline & Height $(\mathrm{cm})$ & 3.28 & 0.21 & 1.13 & $15.70 * *$ \\
\hline & Weight (kg) & 0.41 & 0.44 & 0.05 & 0.93 \\
\hline & Chest area $\left(\mathrm{m}^{2}\right)$ & -256.09 & 146.98 & -0.07 & -1.74 \\
\hline
\end{tabular}

Note: $B$ - unstandardized coefficient; $S E$ - standard error; $\beta$ - standard coefficient; $t$ - Student's $t$; *significant at $p<.05 ; * *$ significant at $p<.001$

The earlier grouping of eight occupational groups representing the work area was an efficient grouping scheme on high contrast to exposure level between the work areas. This study established prediction equations for lung function (PEFR) in male tobacco workers in Nigeria. The subjects were healthy male young Nigerians in a 
tobacco company in Ibadan. There was no cigarette smoker among the subjects who were grouped into directly exposed and indirectly exposed groups. The finding in this study showed that exposure to respiratory dust was significantly correlated with percentage cross-shift decreases in PEF values of the workers in the both directly exposed and indirectly exposed groups.

The mean of percentage cross-shift change showed that of all the departments, the workers (with the highest mean) in PMD section were mostly affected by the dust, followed by workers in SMD while workers in filter rod and maintenance departments were less affected. This means that with time, the lung function impairment and respiratory symptoms in the workers of these departments may worsen and it would be necessary to take precautionary measures. The mean values of PEFR of $492.00( \pm 16.36) \mathrm{L} / \mathrm{min}$ and $512.75( \pm 21.48)$ obtained in the present study for directly exposed and indirectly exposed workers were higher than the mean of $441( \pm 93.98)$ $\mathrm{L} / \mathrm{min}$ for workers in a tobacco company in India with $\leq 5$ years of experience as reported by Ghosh and Barman [4]. These differences may be due to the differences in age, height, and weight as the means of age, height and weight in this study were $32.18( \pm 5.42)$ years, $168.00( \pm 6.69) \mathrm{cm}$ and $66.63( \pm 7.63) \mathrm{kg}$ respectively. However, the means of age, height, and weight in the study of Ghosh and Barman [4] were $30( \pm 6.38)$ years, 160.60 $( \pm 11.23) \mathrm{cm}$ and $53.60( \pm 9.90) \mathrm{kg}$ respectively. Uitti et al. [27] found a significant decrease in FEV1 during the work shift and an excess of chest tightness among non-smoking tobacco workers.

The low-level of PEFR in some indirectly exposed workers may be because some workers engage in other strenuous and dusty activities outside tobacco work. Sunter et al. [28] concluded that exposure to tobacco dust for long periods affected the lung functions and some measures should be taken in the working area to reduce the amount of tobacco dust and prevent its inhalation.

The study showed that there were significant differences $(\mathrm{p}<0.001)$ between the PEFR values of directly exposed and indirectly exposed group necessitating the need to develop models for both. The prediction equation established in a study took only height into account [29] and since age did not contribute significantly to the equation, their equation was derived without including age. In this study, it was observed that age was significant $(\mathrm{p}<0.001)$ in the formulation of the predictive models for PEFR of both the directly exposed and indirectly exposed groups. This agrees with the report of Njoku and Anah [30].

It was also observed that height was a significant factor to determine a worker's PEFR in both the directly exposed and indirectly exposed groups with $\mathrm{p}<0.05$ and this agrees with the work of Suzanne et al. [29]. Weight was not significant $(\mathrm{p}>0.05)$ and this also agrees with the work of Njoku and Anah [30]. Also, Chehreh et al. [31] affirmed that weight contributed comparatively little, hence their equation was derived without weight. Dhungel et al. [32] noted that one of the easiest ways to assess the lung capacity and ventilatory function of workers is to use PEFR which depends on age, body size, physical activity, ethnicity and environmental conditions.

The confounding factors of age, gender, height, weight, chest area and length of exposure to determine PEFR for the tobacco workers were observed to be correlated with PEFR either positively or negatively. Years of exposure was not one of the best predictors of PEFR, though expected, probably because of the occasional use of PPE during the operation and within the factory premises to reduce the effect of tobacco dust. Besides, some workers may be involved in other activities outside the factory, which might affect the PEFR. It is necessary to enforce the use of PPE to reduce workers' exposure to tobacco dust in the workplace. Mohammadyan and Baharfar [33] suggested that besides the use of PPE by workers, all dried tobacco leaves should pass through a vacuum room before any manipulation and that an air suction system should be used to clean machines and all other surfaces.

\section{CONCLUSIONS}

In conclusion, this study showed that workers in a tobacco factory are exposed to tobacco dust irrespective of their department and that the models could be used to determine the PEFR of workers in a tobacco manufacturing company.

The findings in this study may represent the situation in tobacco processing plants in Nigeria and other African countries. 


\section{REFERENCES}

[1] Singleton, W.T., Introduction to ergonomics, Geneva: World Health Organization, 1972.

[2] Merenu, I.A., Mojiminiyi, F.B.O., Njoku, C.H., Ibrahim, M.T.O., The effect of chronic cement dust exposure on lung function of cement factory workers in Sokoto, Nigeria, African Journal of Biomedical Research, vol. 10, no. 2, 2007, p.139-143.

[3] Mustjbegovic, J., Zuskin, E., Schachter, E.N., Kern, J., Luburic-Milas, M., Pucarin, J., Respiratory findings in tobacco workers, Chest, vol. 123, no. 5, p. 1740-1748.

[4] Ghosh, T., Barman, S., Respiratory problems of workers in the Zarda Industry in Kolkata, India, International Journal of Occupational Safety and Ergonomics, vol. 13, no. 1, 2007, p. 91-96.

[5] Rappaport, S.M., Lyles, R.H., Kupper, L.L., An exposure assessment strategy accounting for the within- and between- worker sources of variability, Annals of Occupational Hygiene, vol. 39, 1995, p. 469-495.

[6] Akanbi, O.G., Ismaila, O., Olaoniye, W., Oriolowo, K.T., Odusote A., Assessment of post-work peak expiratory flow rate of workers in cement company, Sigurnost (Safety), vol. 56, no. 4, 2014, p. 315 - 322.

[7] Crapo, R.O., Pulmonary- function testing, New England Journal of Medicine, vol. 331, 1994, p. 25-30.

[8] Ghosh, S.K., Parikh, J.R., Gokani, V.N., Rao, N.M., Doctor, P.B., Occupational health problems among tobacco processing workers, a preliminary study, Archives of Environmental Health, vol. 40, 2012, p. 318-321.

[9] Kromhout, H., Symanski, E., Rappaport, S.M., Comprehensive evaluation of within- and between-worker components of occupational exposure to chemical agents, Annals of Occupational Hygiene, vol. 37, no. 3, 1993, p. $253-270$.

[10] Goldberg, M., Hemon, D., Occupational epidemiology and assessment of exposure, International Journal of Epidemiology, vol. 22, no. 2, 1993, p. S5-S9.

[11] Sauleau, E.A., Wild, P., Hours, M., Comparison of measurement strategies for prospective occupational epidemiology, Annals of Occupational Hygiene, vol. 47, no. 2, 2003, p. 101-110.

[12] Loomis, D., Kromhout, H., Exposure variability: Concepts and applications in occupational exposure, American Journal of Industrial Medicine, vol. 45, no. 1, 2004, p. 113-122.

[13] Seixas, N.S., Sheppard, L., Maximising accuracy and precision using individual and group exposure assessments, Scandinavian Journal of Work, Environment and Health, vol. 22, 1996, p. 94-101.

[14] Symanski, E., Kupper, L.L., Kromhout, H., An investigation of systematic changes in occupational exposure, American Industrial Hygiene Association Journal, vol. 57, 1996, p. 724-735.

[15] Mulhausen, J.R., Damiano, J., Analysis of variance for refining similar exposure groups: A strategy for assessing and managing occupational exposures, American Industrial Hygiene Association Journal, vol. 59, 1998, p. 287-304.

[16] Viegi, G., Paggiaro, P.L., Begliomini, E., Vaghetti, E., Paoletti, P., Giuntini, C., Respiratory effects of occupational exposure to tobacco dust, British Journal of Industrial Medicine, vol. 43, 1986, p. 802-808.

[17] Mwaiselage, J., Moen, B., Bratveit, M., Acute respiratory health effects among cement workers in Tanzania: An evaluation of a simple health surveillance tools, International Archives of Occupational and Environmental Health, vol. 79, no. 1, p. 49-56.

[18] Abdel Rasoul, G.M., El-Sobky, M.K., Michael, A.A., El Dalatony, M.M., Lucchini R., Respiratory disorders among workers in a tobacco factory, Egyptian Journal of Occupational Medicine, vol. 34, no. 2, 2010, p. 255-266.

[19] Mengesha, Y.A., Bekele, A., Effect of acute exposure to different occupational dusts on pulmonary function indices of factory workers in Ethiopia, African Newsletter of Occupational Health and Safety, vol. 79, 1997, p. 49-56.

[20] Lander, F., Gravesen, S., Respiratory disorders among tobacco workers, British Journal of Industrial Medicine, vol. 45, 1988, p. 500-502.

[21] World Health Organization (WHO), Early detection of occupational lung disease, Geneva Switzerland, 1986.

[22] Kjaergaard, S.K., Pedersen, O.F., Frydenberg, M., Respiratory disease and lung function in a tobacco industry, Archives of Environmental Health, vol. 44, no. 3, 1989, p. 164 -170.

[23] Lebowitz, M.D., Burrows, B., BMRC and NHLI respiratory questionnaires and a new self completion questionnaire, American Review of Respiratory Disease, vol. 113, no. 5, 1976, p. 627- 635.

[24] Cotes, J.E., Chinn, D.J., MRC questionnaire (MRCQ) on respiratory symptoms, Occupational Medicine, vol. 57 , no. 1,2007 , p. 388- 389.

[25] Ismaila, S.O., Charles-Owaba, O.E., A quantitative approach for establishing safe weight of lift. Engineering Review, vol. 32, no. 1, 2012, p. 1-8. 
[26] Ismaila, S.O., Akanbi, O.G., Olaoniye, W., Model for predicting peak expiratory flow rate of Nigerian workers in a cement factory in Itori, Ogun State, Nigeria, International Journal of Occupational Safety and Ergonomics, vol. 21, no. 4, 2015, p. 547-550.

[27] Uitti, J., Nordman, H., Huuskonen, M.S., Roto, P., Husman, K., Reiman, M., Respiratory health of cigar factory workers, Occupational and Environmental Medicine, vol. 55, 1998, p. 834-839.

[28] Sunter, A.T., Bagiric, F., Dundar, C., Marangoz A., Peksen Y., Lung functions in workers exposed to tobacco dust, Turkish Journal of Medical Science, vol. 31, 2001, p. 143-146.

[29] Suzanne, M.B., David, A.A., Mark, W.C., Pulmonary function test outcome in healthy Nawajo native American adolescents, American Journal Respiratory and Critical Care Medicine, vol. 150, 1994, p. 1150-1153.

[30] Njoku, C.H., Anah, C.O., Reference values for Peak expiratory flow rate in adults of African descent, Tropical Doctor, vol. 34, 2004, p. 135-140.

[31] Chehreh, M.N., Young, R.C., Viaene, H., Ross, C.W., Scott, R.B., Spirometry standards for healthy innercity black children, American Journal of Diseases in Children, vol. 126, no. 2, 1973, p. 159-163.

[32] Dhungel, K.U., Parthasarathy, D., Dipali, S., Peak expiratory flow rate of Nepalese children and young adults, Kathmandu University Medical Journal, vol. 6, no. 3, 2008, p. 346-354.

[33] Mohammadyan, M., Baharfar, Y., Evaluation of tobacco dust and designing of local exhaust ventilation (lev) systems in a tobacco processing industry, International Journal of Occupational Hygiene, vol. 4, 2012, p. 47-52. 